Original article

\title{
The incidence rate of hepatosteatose in virus carriers with inactive Hepatitis B
}

\author{
Fatih Demircan ${ }^{1}$, Nevzat Gözel ${ }^{2}$, Affan Denk ${ }^{2}$, Faruk Kılınç ${ }^{3}$ \\ ${ }^{1}$ Private Cagri Medical Center, Elazig, Turkey \\ ${ }^{2}$ Firat University, Elazig, Turkey \\ ${ }^{3}$ Dicle University, Diyarbakir, Turkey
}

Received 6 November 2013, Revised 2 January 2014, Accepted 5 March 2014

(C) 2013, Demircan F., Gözel N., Denk A., Kılınç F.

(C) 2014, Russian Open Medical Journal

Abstract: Objective - The aim of this study is to examine the data retrospectively from patients with inactive HBV whose livers were evaluated by ultrasonography and to investigate hepatosteatosis as well as related parameters in this patient group.

Material and Methods - In our study, the data of 134 patients, who have applied to the Internal Disease Polyclinic of Elazığ Çağrı Private Medical Center between January 2010 and August 2013 being diagnosed as carriers for inactive HBV and then performed abdominal ultrasonography, were evaluated retrospectively. Information for each patient was accessed by means of both the internal disease polyclinic in our hospital and patient epicrisis reports. The observed levels of plasma trigliserides, LDL cholesterol, AST, ALT, GGT, and ALP were all recorded.

Findings - Out of 134 subjects, 72 were male while 62 were female accounting for $54 \%$ and $46 \%$, respectively. The mean age of the patients were found to be $44.8 \pm 10.6$ years old. Hepatosteatosis was found in 92 patients accounting for $68.7 \%$. The mean of age in some patients diagnosed with steatosis was found $50.1 \pm 7.6$ years, while the others without steatosis was $33.2 \pm 6.0$ years suggesting a significant difference compared to the former $(p=0.001)$. Furthermore, a consistency in difference was also found between these two groups with and without hepatosteatosis in terms of average triglyceride levels $(p=0.001)$. The mean GGT levels were consistently higher in the group with hepotosteatosis $(p=0.004)$. No significant difference was found between these two groups regarding their mean cholesterol levels of AST, ALT, ALP, and LDL.

Conclusion - In patients with asymptomatically HBV infection, an increased risk for hepatosteatosis comes along with an increased levels of plasma triglycerides and GGT in the course of aging.

Keywords: inactive HBV carriers, hepatosteatosis, ultrasonography

Cite as Demircan F, Gözel N, Denk A, Kılınç F. The incidence rate of hepatosteatose in virus carriers with inactive Hepatitis B. Russian Open Medical Journal 2014; 3: 0205.

Correspondence to Fatih Demircan. E-mail: fatihdemircan95@gmail.com. Tel: +90 5313059539. Fax: +90 4242242338.

\section{Introduction}

Hepatosteatosis (i.e. hepatic lipidosis) is a condition characterized by an increased percentage of accumulated fat, that are triglycerides (TG) in particular, in liver more than $5 \%$ by weight or more than $5 \%$ of hepatocytes to be filled with fat vacuoles [1]. The incidence of hepatosteatosis has gradually been increasing along with an increased incidence of metabolic syndromes worldwide [2]. The rate of hepatosteatosis in society is about $30 \%$ $[3,4]$ while the frequency can reach up to $70 \%$ and $90 \%$ in patients either obese or with type 2 diabetes [1-5]. Other common causes of hepatosteatosis include alcohol consumption, drugs and nutrition disorders [2]. Although both hepatosteatosis and Hepatitis $\mathrm{C}$ were most often indicated to break out together in previous studies, limited studies are available in explaining the relationship between chronic Hepatitis $\mathrm{C}$ and steatotisis. Even worse, only a few studies in examining hepatosteatosis prevalence and its effects on the course of disease can be found in Hepatitis B virus (HBV) carriers in particular [6].
With the present study, we purposed to examine hepatosteatosis and related parameters in this patient group by a retrospective analyze of the data from chronic HBV carriers who were also assessed with liver ultrasonography (USG).

\section{Material and Methods}

In our study, the data from 134 patients, who have applied to the Internal Disease Polyclinic of Elazığ Çağrı Private Medical Center between January 2010 and August 2013 being diagnosed as carriers for inactive HBV and then performed abdominal ultrasonography, were evaluated retrospectively. In these patients, the incidence rate for hepatosteatosis was investigated and hepatosteatosis was scaled as following:

Stage-0: No hepatosteatosis;

Stage-1: Mild;

Stage-2: Moderate; and

Stage-3: Severe. 
Table 1. The comparison of both the groups with and without hepatosteatosis in terms of age and gender

\begin{tabular}{|c|c|c|c|c|c|}
\hline Gender & Hepatosteatosis & Age & $N$ & $\%$ & Age Interval \\
\hline \multirow[t]{3}{*}{ Female } & No Hepatosteatosis & $31.2 \pm 5.2$ & 21 & 15.7 & $23-40$ \\
\hline & With Hepatosteatosis & $51.8 \pm 8.0$ & 41 & 30.6 & $33-66$ \\
\hline & Total & $44.8 \pm 12.1$ & 62 & 46.3 & $23-66$ \\
\hline \multirow[t]{3}{*}{ Male } & No Hepatosteatosis & $35.1 \pm 6.2$ & 21 & 15.7 & $26-46$ \\
\hline & With Hepatosteatosis & $48.8 \pm 7.1$ & 51 & 38.1 & $34-65$ \\
\hline & Total & $44.8 \pm 9.2$ & 72 & 53.7 & $26-65$ \\
\hline \multirow[t]{3}{*}{ Total } & No Hepatosteatosis & $33.2 \pm 6.0$ & 42 & 31.3 & $23-46$ \\
\hline & With Hepatosteatosis & $50.1 \pm 7.6$ & 92 & 68.7 & $33-66$ \\
\hline & Total & $44.8 \pm 10.6$ & 134 & 100 & $23-66$ \\
\hline
\end{tabular}

Table 2. The comparison of biochemical workups and statistical findings between those groups with and without hepatosteatosis

\begin{tabular}{|c|c|c|c|c|c|c|c|}
\hline Hepatosteatosis & & $T G$ & $A L T$ & $A S T$ & $L D L$ & $G G T$ & $A L P$ \\
\hline \multirow[t]{2}{*}{ No Hepatosteatosis } & Mean & $199.5 \pm 72$ & $27.6 \pm 7.5$ & $29.4 \pm 8.8$ & $125.6 \pm 33$ & $81.4 \pm 44$ & $68.5 \pm 31$ \\
\hline & Interval & $102-455$ & $14-41$ & $12-42$ & $78-190$ & $24-214$ & $24-186$ \\
\hline \multirow[t]{2}{*}{ With Hepatosteatosis } & Mean & $254.2 \pm 92$ & $27.7 \pm 7.9$ & $28.1 \pm 8.6$ & $135.1 \pm 38$ & $109.5 \pm 65$ & $58.7 \pm 24$ \\
\hline & Interval & $132-641$ & $12-43$ & $14-45$ & 78-198 & $24-245$ & 24-167 \\
\hline \multirow[t]{2}{*}{ Total } & Mean & $237.1 \pm 89$ & $27.6 \pm 7.7$ & $28.5 \pm 8.6$ & $132.1 \pm 37$ & $100.7 \pm 61$ & $61.8 \pm 27$ \\
\hline & Interval & $102-641$ & $12-43$ & $12-45$ & 78-198 & $24-245$ & $24-186$ \\
\hline P level & & 0.004 & 0.978 & 0.402 & 0.171 & 0.004 & 0.510 \\
\hline
\end{tabular}

The patients considered as inactive $\mathrm{HBV}$ carriers whose $\mathrm{HBsAg}$ (Hepatitis B surface antigen) positivity has remained more than 6 months along with a negative $\mathrm{HBeAg}$ (Hepatitis $\mathrm{B}$ e-antigen) and a positive Anti-HBe having normal levels of aspartat aminotransferase (AST) / alanin aminotransferase (ALT) as well as the plasma level of HBV-DNA under $2.000 \mathrm{IU} / \mathrm{mL}$, and a negative hepatitis delta virus (HDV) and hepatitis $C$ virus (HCV) without any findings of a further liver disease (as having normal albumin, prothrombin, and platelet counts) were all included in this study [7]. Information for each patient was accessed via patient epicrisis reports filled by the internal disease polyclinic in our hospital. The observed levels of plasma triglicerides, LDL cholesterol, AST, ALT, GGT, and ALP were all recorded.

The patients who previously administered antiviral drugs with positive results of anti-HCV or anti-HDV, using hepatotoxic drugs or alcohol, and the patients with autoimmune or metabolic liver disorders were all excluded from the study. For a statistical evaluation, SPSS with the version 16.0 was used. Normal distributions were tested with Kolmogorov- Smirnov test with Lilliefors correction. Quantitative data were presented as mean \pm Standard deviation (S.D). Statistical differences among the groups were identified with Student's t- test. Chi-square method and student t-test were used to compare the frequencies and mean values, respectively. Statistically, $p<0.05$ was considered to be a consistent inequation.

\section{Results}

Out of 134 subjects, 72 were male while 62 were female accounting for $54 \%$ and $46 \%$, respectively. The mean age of the patients were found to be $44.8 \pm 10.6$ years old (the age ranging between 23 and 66 years). The incident rates were close in both males and females with no significant consistency in terms of age and gender. Hepatosteatosis was found in 92 patients (68.7\%). The mean age of patients with steatosis was $50.1 \pm 7.6$ years, while it was found $33.2 \pm 6.0$ years for those without steatosis resulting a significant difference between them $(p=0.001) .71$ patients with hepatosteatosis (53\%) were classified as Grade-1, while 15 (11,2\%) and $6(4.5 \%)$ patients were as Grade-2 and Grade-3, respectively. No significant difference was found between the duration of disease and lipoidosis degree in subjects with steatosis $(p=0.43)$. In additional USG findings, gallstone, liver hemangioma, and a past cholecystectomy were found in 8,7 , and 13 patients, respectively. 51 subjects with hepatosteatosis (38\%) were male having a mean age of $48.8 \pm 7.1$ years, while only 21 patients without any steatosis (15.7\%) were male having a mean age of $35.1 \pm 6.0$ years. Table 1 shows a comparison of both the groups with and without hepatosteatosis in terms of age and gender.

The mean level of TG was $237.1 \pm 89.6$ in all patients, while it was $199.5 \pm 72.0$ and $254.2 \pm 91.0$ for those only without fatty liver and with hepatosteatosis, respectively. Only for the subjects with hepatosteatosis stage-3, the value was found $340.3 \pm 197.2$. A significant difference was found in groups with and without hepatosteatosis regarding their average levels of TG $(p=0.001)$. The average levels of GGT were significantly high in the group with hepatosteatosis $(p=0.004)$. No consistent difference was found in both groups among their AST, ALT, ALP, and LDL cholesterol levels (Table 2). Table 2 provides the comparison of biochemical workups and related statistical findings between those groups with and without hepatosteatosis.

\section{Discussion}

HBV infection is a public health issue which is commonly seen as both acute and chronic cases all over the world. In our country, about 3.5 millions of people are infected with $\operatorname{HBV}[8,9]$. Therefore, it is of great importance to diagnose chronic HBV infection as well as to prevent the modes of transmission and to start an early treatment. Chronic HBV infection can appear in a wide range of cases from asymptomatic carriage to cirrhosis. One of the liver findings observed among asymptomatic (inactive) carriers is hepatosteatosis, which is commonly more prevalent in inactive HBV carriers compared to HCV [2]. Since histological workup is difficult to perform in order to make a diagnose, USG scanning can be used as the most practical and invasive method [10]. USG yields with a sensitivity of $83 \%$ and a specificity of $100 \%$ [11]. In this study, the frequency of hepatosteatosis in inactive HBV carriers was found $68.7 \%$ which suggested an increased rate compared to the general population. That $38.1 \%$ of the patients with steatosis was male, contradicts with the fact that the fatty liver is mostly seen among women according to the literature. 
HBV infection mostly occurs during childhood, adolescence, and young adulthood [2]. Yalçın at al. reported in their study with 179 patients that the mean age of acquiring HBV infection was 26.9 years [12]. The age of acquiring infection was unkown in our study, however, the mean age of subjects during application was found $44.8 \pm 10.6$ years with the ages ranging from 23 to 66 years. Increased mean age of the subjects participated in our study might be explained by that nearly all the patients applied to our polyclinic were above 18 in age.

Although viral hepatitis is not a common cause of hepatosteatosis, it is important as it affects about $5 \%$ of both our society and world population [13]. In past, chronic hepatitis $C$ has frequently associated with hepatosteatosis, and it was suggested that hepatosteatosis occured under the effect of Hepatitis $C$ virus [2]. In another study, the patients with chronic hepatitis B and C was compared resulting an increased frequency of steatosis in patients with chronic hepatitis C [14]. In another study, hepatosteatosis was found concurrently in $27 \%$ of the patients with chronic hepatitis B [15]. Ökten et. al. reported the existence of hepatosteatosis in $13.4 \%$ of 372 patients carrying an asymptomatically chronic HBsAg [13]. The present study indicated a high level of steatosis (68.7\%) in inactive HBV carriers. This percentage was significantly higher than those of chronic hepatitis carriers in literature.

In their study with chronic hepatitis B patients, Altıparmak et al. reported higher levels of mean age, body mass index (BMI), cholesterol, and TG in the patient group with steatosis. Additionally, they also found no significant difference between the patient groups with and without steatosis in terms of AST, ALT, ALP, GGT and viral load, steatosis was suggested to be associated with obesity and hyperlipidemia rather than viral effects [6]. In our study, the levels of TG and GGT as well as age were found to be higher in the patient group withhout steatosis than those of the non-steatosis group. That a higher mean of age and median time of disease leading to a prolonged exposure to the virus at older ages supports the likelihood of viral effect on developing steatosis.

Some clinical, biochemical, serological and molecular tests can be used at regular intervals in order to monitor chronic HBV carriers. In addition, the patients should be monitored by means of USG and alpha-feto protein scanning each 6 months in order to determine the complications $[7,16]$. Abdominal USG provides excellent information on steatosis and other constitutional findings. For example, 8 patients were developed gallstone, and 7 patients were developed liver hemangioma, as well as 13 patients were found to have a past cholecystectomy in our patient group.

\section{Conclusion}

The risk for hepatosteatosis increased in the presence of high triglycerides and gamma glutamyl transferase in the patients involved in this study who developed asymptomatically HBV infection along with hepatic lipidosis as they grew older. Any patient known to be an HBV carrier is definitely supposed to perform abdominal USG during initial assessment. Performing USG provides benefits in future comparison on the detection of pathological findings other than steatosis. Further studies are required for this field in which a larger series of data should be examined.

Conflict of interest: none declared.

\section{References}

1. Satman I, Kocabay G. Diabetes mellitus and fatty liver: review. Turkiye Klinikleri J Med Sci 2000; 126: 176-88.

2. Farrell GC, Larter CZ. Nonalcoholic fatty liver disease: from steatosis to cirrhosis. Hepatology 2006; 43: 99-112. (doi: 10.1002/hep.20973) (PMID: 16447287)

3. Kirovski G, Schacherer D, Wobser $\mathrm{H}$, Huber $\mathrm{H}$, Niessen $\mathrm{C}$, Beer $\mathrm{C}$, et al. Prevalence of ultrasound-diagnosed non-alcoholic fatty liver disease in a hospital cohort and its association with anthropometric, biochemical and sonographic characteristics. Int J Clin Exp Med 2010; 3: 202-210. (PMID: 20827318) (PMCID: PMC2929946)

4. Younossi ZM. Review article: current management of non-alcoholic fatty liver disease and non-alcoholic steatohepatitis. Aliment Pharmacol Ther 2008; 28: 2-12. (PMID: 18410557) (doi: 10.1111/j.1365-2036.2008.03710.x)

5. Sookoian S, Burgueno AL, Castano G, Pirola CJ. Should nonalcoholic fatty liver disease be included in the definition of metabolic syndrome? A cross-sectional comparison with adult treatment panel III criteria in nonobese nondiabetic subjects: response to Musso et al. Diabetes Care 2008; 31(5): e42; author reply e43. (PMID: 18445722) (doi: 10.2337/dc08-0027)

6. Altıparmak E, Koklu S, Yalinkilic M, Yuksel O, Cicek B, Kayacetin E, Sahin T. Viral and host causes of fatty liver in chronic hepatitis B. World J Gastroenterol 2005; 11: 3056-3059. (PMID: 15918189)

7. Lok AS, McMahon BJ. Chronic hepatitis B. Hepatology 2007; 45(2): 507-539. (PMID: 17256718) (doi: 10.1002/hep.21513)

8. Birengel E, Tekeli E. The epidemiology of chronic hepatitis. Köksal i, Leblebicioğlu H. Current approaches to diagnosis and treatment of chronic hepatitis (First edition). Ankara: Scientific Medicine Publications, 2009: 11-25.

9. Çaylan R, Keske Ş. The epidemiology of hepatitis $B$ and definitions. Chronic Hepatitis B. Ankara, 2009: 9-17.

10. Marn CS, Bree RL, Silver TM. Ultrasonography of liver: technique and focal and diffuse disease. Radiol Clin North Am 1991; 29: 1151-1170. (PMID: 1947039)

11. Yajima $Y$, Ohta $K$, Narui $T$, Abe $R$, Suzuki $H$, Ohtsuki $M$. Ultrasonographical diagnosis of fatty liver: signifcance of the liver kidney contrast. Tohoku J Exp Med 1983; 139: 43-50. (PMID: 6220488) (doi: 10.1620/tjem.139.43)

12. Yalcin K, Degertekin H, Yildiz F, Celik Y. Markers of disease activity in chronic hepatitis B virus infection. Clin Invest Med 2003; 26: 27-34. (PMID: 12659467)

13. Ökten A, Demir K, Çakaloğlu Y. Chronic asymptomatic HBsAg carriers (Evaluation of 372 cases). T Klin Gastroenterohepatoloji 1996; 7: 178183.

14. Czaja AJ, Carpenter HA, Santrach PJ, Moore SB. Host- and diseasespecific factors affecting steatosis in chronic hepatitis C. J Hepatol 1998; 29: 198-206. (PMID: 9722200)

15. Czaja AJ, Carpenter HA. Sensitivity, specificity, and predictability of biopsy interpretations in chronic hepatitis. Gastroenterology 1993; 105: 1824-1832. (PMID: 8253358)

16. Sharma SK, Saini N, Chwla Y. Hepatitis B Virus: Inactive carriers. Virology Journal 2005; 2: 82. (doi: 10.1186/1743-422X-2-82) (PMCID: PMC1253537)

\section{Authors:}

Fatih Demircan - Specialist, Department of Internal Medicine, Private Cagri Medical Center, Elazig, Turkey;

Nevzat Gözel - Assistant Professor, Department of Internal Medicine, Medical Faculty, Fırat University, Elazig, Turkey;

Affan Denk - Assistant Professor, Department of Infectious Disease, Medical Faculty, Firat University, Elazig, Turkey;

Faruk Kılınç - Assistant Professor, Department of Internal Medicine, Medical Faculty, Dicle University, Diyarbakir, Turkey. 